\title{
High Prevalence and Genotypic Characterization of Metallo- $\beta$-Lactamase (MBL)-Producing Acinetobacter spp. Isolates Disseminated in a Korean Hospital
}

Jong Hwa Yum

Department of Clinical Laboratory Science, Dongeui University, Busan, Korea

\section{국내 대학병원에서 분리된 Metallo- $\beta$-Lactamase (MBL) 생성 Acinetobacterspp. 분리주의 높은 출현율과 유전형 특징} 염종화

동의대학교 임상병리학과

\section{ARTICLE INFO}

Received September 22, 2019

Revised $1^{\text {st }}$ October 2, 2019

Revised $2^{\text {nd }}$ October 7, 2019

Accepted October 8, 2019

\section{Key words}

Acinetobacterspp.

bla|mp-6

blavim-2

Carbapenem resistant

Metallo- $\beta$-lactamase

\begin{abstract}
Carbapenem resistance, mediated by the major acquired metallo- $\beta$-lactamase (MBL) genes, has been increasingly reported, particularly for clinical isolates of Acinetobacter spp. Of the 191 nonduplicate clinical isolates of the carbapenem-nonsusceptible Acinetobacterspp. evaluated, 125 isolates (65.4\%) were positive for the modified imipenem or meropenem-Hodge test, and 49 isolates (25.7\%) were positive for the imipenem-EDTA+SMA double disk synergy test (DDS). PCR and sequencing of the blaviM-2-allele and blaimp-1-allele showed that 29 A. baumannii isolates and 1 A. calcoaceticus isolate had blavim-2, whereas $16 \mathrm{~A}$. baumannii isolates and $2 \mathrm{~A}$. calcoaceticus isolates had bla|MP-6; 1 isolate of the $A$. genomospecies 3 had blavIM-2 and blaAIM- 1 . All the above MBL genes belong to class 1 integron. The size of class 1 integron encompassing blaviM-2 or bla from $2.8 \mathrm{~kb}$ to $3.2 \mathrm{~kb}$ in clinical isolates of $A$. baumannii, and $3.2 \mathrm{~kb}$ to $3.5 \mathrm{~kb}$ in clinical isolates of $A$. genomospecies 3. blavim-2 was most often located first or second in the class 1 integron, and these integrons often included aacA4. Due to dispersion of the MBL-producing Acinetobacterspp. as well as integron, which may encompass various resistance genes, there is an expectation for the increase of multidrug resistant Gram-negative bacteria, including resistance of carbapenems such as imipenem or meropenem. Hence, the development of new antimicrobial agents for treating severe Acinetobacterspp. infections is needed.
\end{abstract}

Copyright $\odot 2019$ The Korean Society for Clinical Laboratory Science. All rights reserved.

\section{서 론}

다제 내성 Acinetobacter spp.에 의한 감염이 증가하고 있

* Corresponding author: Jong Hwa Yum

Department of Clinical Laboratory Science, Dongeui University, 176 Eomgwang-ro, Busanjin-gu, Busan 47340, Korea

E-mail: auxotype@deu.ac.kr

* ORCID: https://orcid.org/0000-0001-9264-1347
어 이들 세균에 의한 감염증 치료에 어려움이 자주 발생하고 있 다[1]. 이들 균종은 신속한 집락화와감염으로 인해 병원 환경에 서 가장 까다로운 병원균 중 하나로 취급된다. Acinetobacter spp.은 폐렴, 패혈증, 심내막염, 창상감염, 요로감염, 수막염 등 다양한 감염증의 원인균으로 알려져 있으며[1-5], 주요한 원내 감염균이기도 하다[6]. Carbapenem은 Acinetobacterspp. 감염에 가장 우수한 약제로 알려져 있으나, carbapenem 내성 
Acinetobacterspp. 의 증가를 막기위해 이들 약제는 제한적으 로 사용하고 있다.

Carbapenem 내성에 관여하는 기전은 carbapenem 가수 분해 $\beta$-lactamase (carbapenemase), 막 투과 감소 및 efflux pump의 활성이 있다[7, 8]. Carbapenemase는 serine- $\beta$-lactamase와 metallo- $\beta$-lactamase (MBL)가 주 요 효소이다. MBL은 분자구조에 따라 6가지 형으로 나뉘며, IMP, VIM, GIM, SIM, AIM 및 SPM 형이 있다[9-11]. 이들 $\mathrm{MBL}$ 중 $\mathrm{IMP}, \mathrm{VIM}$ 및 $\mathrm{SIM}$ 과 같은 $\mathrm{MBL}$ 유전자는 흔히 integron에 위치하여 플라스미드 등과 관련하여 동종간 혹은 이종간 전파가 용이하다[10]. IMP 및 VIM형 및 그 외 class B metallo- $\beta$-lactamase 생성 그람음성 막대균이 임상 검체에 서 분리율이 계속적으로 증가하고 있다[12, 13]. MBL 중 VIM 의 경우 1997년 프랑스에서 분리된 P. aeruginosa에서 class 1 integron에 위치한 blaviM-2가 검출되었으며[14], 여러 나라 에서 점차 출현율이 증가하고 있다. 또한, $\mathrm{MBL}$ 유전자 중 하나 인 blaIMP-1은 1988년 일본에서 처음 보고되었으며[15], 이들 $\mathrm{MBL}$ 변이종은 점차 증가하고 전파 확산되고 있다. 2003년 국 내 임상에서 분리한 Acinetobacter spp. 267주중 MBL 생성 균주는 38주(14.2\%)이었으나[16], 계속적인 증가추가에 있다. 또한, 최근 권 등은 IMP-1 생성 균주가 대부분이었고, NDM-1 생성 균주가 2주 검출된 바 있으며, IMP-1과 NDM-1을 동시 생성하는 A. pittir를 국내에서 분리 보고한 바 있다[17]. 따라 서, 본 연구에서는 국내 유행하는 $\mathrm{MBL}$ 생성 Acinetobacter spp. 의 빈도를 조사하고 integron에 위치한 $\mathrm{MBL}$ 유전자의 유 전형을 규명하고 이들 분리 균주들의 항균제 내성 양상을 분석 하고자 하였다.

\section{재료 및 방법}

\section{1. 균주 수집}

2005년부터 2009년까지 국내 경기지역 일개 대학병원 임상 검체에서 분리된 Acinetobacter spp. 중 imipenem 혹은 meropenem에 대하여 비감수성 균주 191주를 수집하였으며, 한 환자에서 중복 분리된 균주는 제외하였다. 균종 동정은 전통 적인 생화학방법과 상품화된 키트(ID $32 \mathrm{GN}$ system, bioMerieuex, Marcy-l'Etoile, France)를 이용하였다.

\section{2. 분자유전학적 동정}

$16 \mathrm{~S} \mathrm{rRNA}$ 유전자 염기서열 분석을 통해 균종 동정하였다. 시험 균주를 부유시킨 멸균수 $100 \mu \mathrm{L}$ 를 $100^{\circ} \mathrm{C}$ 에서 12 분간 중
탕 후 $4^{\circ} \mathrm{C}$ 에서 $13,000 \mathrm{rpm}$ 으로 2 분간 원심분리한 후 상청액 $10 \mu \mathrm{L}$ 를 주형 DNA로 사용하여 중합효소연쇄반응 을 시행하였 다. 시발체는 5'-AGA GTT TGA TCC TGG CTC AG-3'과 5'AAG GAG GTG ATC CAG CCG CA-3'를 사용하였으며, Mastercycler gradient (Eppendorf, Hamburg, Germany) 를 이용하여 $16 \mathrm{~S} \mathrm{rRNA} \mathrm{유전자를} \mathrm{증폭시켰다[17].} \mathrm{중합효소연}$ 쇄반응 조건은 $94^{\circ} \mathrm{C} 5$ 분 predenaturation 후, $94^{\circ} \mathrm{C} 20$ 초 denaturation, $50^{\circ} \mathrm{C} 40$ 초 annealing, $72^{\circ} \mathrm{C} 2$ 분 extension 의 과정을 35 회 반복 후 $72^{\circ} \mathrm{C} 5$ 분 extension을 실시하였다. 중 합효소연쇄반응 산물은 전기영동하여 band를 확인한 후에 QIAquick Gel Extraction kit (QIAGEN, Hilden, Germany)를 이용하여 증폭된 $\mathrm{DNA}$ 를 정제하였다. 정제된 DNA는 ABI Prism 3100 Genetic Analyzer (Applied Biosystems, Foster city, CA, USA)를 사용하여 유전자의 염 기서열을 GenBank data base의 DNA 염기서열과 비교분석 하였다.

\section{Carbapenemase 생성 균주의 선별}

Imipenem 혹은 meropenem을 이용한 Hodge 변법 시험 을 시행하고, E. coli ATCC 25922를 지시세균으로 이용하였 다. E. coli ATCC 25922를 McFarland No. 0.5 탁도관에 맞 추어 MacConkey agar에 멸균된 면봉을 이용하여 고르게 접종 한 후, 중앙에 imipenem 혹은 meropenem $10 \mu \mathrm{g}$ disk (Oxoid, Cambridge, UK)를 얹고 시험 균을 한줄로 획선하여 $36^{\circ} \mathrm{C}$ 에서 18 시간 배양하였다. 시험 세균 주변을 따라 지시세균 의 성장이 증가하면 양성으로 판독하여, carbapenemase 생 성 Acinetobacter spp.로 감별하여 분리 수집하였다[18-20].

\section{Carbapenem-EDTA+SMA double disk synergy 시험}

Imipenem 혹은 meropenem-Hodge 변법시험에 양성인 균주는 imipenem 혹은 meropenem과 EDTA+sodium mercaptoacetic acid (SMA) double disk synergy 시험 (DDS)을 시행하였다[19, 20]. 시험균주를 McFarland 0.5관 탁도로 조정하여 Muller hinton agar에 고르게 접종한 후, imipenem 혹은 meropenem $10 \mu \mathrm{g}$ disk와760 $\mu \mathrm{g}$ EDTA+2 $\mathrm{mg} \mathrm{SMA} \mathrm{disk}$ 를 가장자리가 $10 \mathrm{~mm}$ 간격으로 놓고 $36^{\circ} \mathrm{C}$ 에서 18 시간 배양하였다. 두 디스크 사이의 억제대가 커지면 $\mathrm{MBL}$ 생 성 균주로 판독하였고, 이들 세균은 $20 \%$ skim milk에 부유하 여 $-70^{\circ} \mathrm{C}$ 에 보관하여 시험에 사용하였다. 


\section{MBL 유전자 분석}

중합효소연쇄반응법(PCR)을 이용하여, $\mathrm{MBL}$ 유전자인 bla $\mathrm{IIMP}_{-1}$, blaviM-2, blaAIM-1, blavim-1, blandM-1 및 blasim-1 유 전자를 검출하였다. 시험에 사용한 시발체는 Table 1에 나타내 었다. 균주를 멸균수 $100 \mu \mathrm{L}$ 에 부유하여 10 분간 중탕하고 $13,000 \mathrm{rpm}$ 에서 2분간 원심후 상청액을 주형 DNA로 이용하 였다. 중합효소연쇄반응 반응은 AccuPower PCR Premix (Bioneer, Daejeon, Korea)에 주형 DNA $1 \mu \mathrm{L}, 20$ pmol의 시발체 $1 \mu \mathrm{L}$, 증류수 $17 \mu \mathrm{L}$ 를 첨가하여 최종 $20 \mu \mathrm{L}$ 으로 반응하 였다. Mastercycler Gradient 5331 (Eppendorf)를 이용하 여 $94^{\circ} \mathrm{C} 4$ 분 predenaturation, denaturation $94^{\circ} \mathrm{C} 30$ 초, annealing $55^{\circ} \mathrm{C} 30$ 초, extension $72^{\circ} \mathrm{C} 45$ 초의 조건으로 30 회 반응하고 $72^{\circ} \mathrm{C} 7$ 분간 extension하여 반응을 종료하였 다. 중합효소연쇄반응 산물의 확인은 $1 \%$ agarose gel에서 100 $\mathrm{V} \mathrm{30}$ 분간 전기영동하고, 중합효소연쇄반응 산물의 크기 추정 을 위하여 500 bp DNA ladder (Takara, Shiga, Japan)를 사 용하였다[9]. 중합효소연쇄반응 산물은 ABI Prism 3100 Genetic Analyzer (Applied Biosystems)를 사용하여 유전자 의 염기서열을 분석하였다.

\section{Integron 유전자 분석}

Class 1 integron은 중합효소연쇄반응법에 의해 검출하였 고, Riccio 등이 제시한 시발체를 사용하였다[21]. 중합효소연 쇄반응 조건은 Levesque 등의 방법을 변형하여 시행하였다 [22]. 중합효소연쇄반응은 3U LA Taq DNA polymerase (Takara, Shiga, Japan)에 주형 DNA $5 \mu \mathrm{L}, 20$ pmol의 시발 체 5'CS-F와3' CS-R $1 \mu \mathrm{L}$ 를 첨가하고, 최종 $100 \mu \mathrm{L}$ 로 반응하 였다. 중합효소연쇄반응은 Mastercycler Gradient 5331
(Eppendorf)를 이용하여 predenaturation $94^{\circ} \mathrm{C} 12$ 분, $94^{\circ} \mathrm{C} 1$ 분, $56^{\circ} \mathrm{C} 1$ 분, $72^{\circ} \mathrm{C} 5$ 분으로 35 회 시행하였다. 매 회 마 다 extension 시간은 5초씩 증가시켰다. Integrase 유전자, intI1, intI2 및 intI3의 검출은 Shibata 등이 제시한 시발체와 중합효소연쇄반응 조건으로 시행하였다[23].

중합효소연쇄반응 산물은 ABI Prism 3100 Genetic Analyzer (Applied Biosystems)를 사용하여 염기서열을 분석 하였다.

\section{7. 항균제 감수성 시험}

항균제 감수성 시험은 CLSI [24]의 권고에 따라 $10^{4}$ colony forming units의 접종액을 Mueller-Hinton agar (Difco Laboratories, USA)에 접종하여 고체한천희석법으로 시행하 였다. E. coli ATCC 25922와 P. aeruginosa ATCC 27853를 항균제 감수성 시험에 참조균주로 사용하였다. 시험에 사용한 항균제는 ampicillin과 cephalothin (Sigma Chemical Co., USA), piperacillin (Wyeth, USA), sulbactam (Pfizer Korea, Seoul, Korea), ceftazidime (GlaxoSmithKline, UK), cefotaxime (Handok, Korea), cefoxitin과 imipenem (Merck Sharp \& Dohme, USA), meropenem (Sumitomo, Japan), aztreonam (Bristol-Myers Squibb, USA), amikacin (Dong-A Pharmaceutical, Seoul, Korea), ciprofloxacin (Sigma-Aldrich, China), 그리고 colistin (Sigma-Aldrich, St. Louis, MO, USA)이었다.

\section{결 과}

1. Carbapenemase 생성 Acinetobacterspp. 선별

국내 대학병원에서 환자에서 분리된 imipenem 혹은 me-

Table 1. Primers used for detection or sequencing of the MBL genes

\begin{tabular}{|c|c|c|c|c|}
\hline Target & Primer & Sequence $\left(5^{\prime}\right.$ to $\left.3^{\prime}\right)$ & Size of product & Gene bank accession number \\
\hline blamp-1 & $\begin{array}{l}\text { IMP1-F } \\
\text { IMP1-R }\end{array}$ & $\begin{array}{l}\text { CAT GGT TTG GTG GTT CTT GT } \\
\text { ATA ATT TGG CGG ACT TTG GC }\end{array}$ & 448 bp & AB753459.1 \\
\hline blavim-2 & $\begin{array}{l}\text { VIM2-FR-F } \\
\text { VIM2-FR-R }\end{array}$ & $\begin{array}{l}\text { ATG TTC AAA CTT TTG AGT AAG } \\
\text { CTA CTC AAC GAC TGA GCG }\end{array}$ & 801 bp & AF191564 \\
\hline blaAIM-1 & $\begin{array}{l}\text { AlM1-F } \\
\text { AlM1-R }\end{array}$ & $\begin{array}{l}\text { ATG AAA CGT CGC TTC ACC CTG } \\
\text { TCA AGG CCG CGC GCC CC }\end{array}$ & 912 bp & AM998375 \\
\hline blavIM-1 & $\begin{array}{l}\text { VIM1-F } \\
\text { VIM1-R }\end{array}$ & $\begin{array}{l}\text { CAC TTC TCG GCG GAG ATT GAA } \\
\text { GTG CTT TGA CAA CGT TCG CT }\end{array}$ & $495 \mathrm{bp}$ & KC417378.1 \\
\hline blandM-1 & $\begin{array}{l}\text { NDM1-F } \\
\text { NDM1-R }\end{array}$ & $\begin{array}{l}\text { TCG CAC CGA ATG TCT GGC AGC A } \\
\text { AAA GCG ATG TCG GTG CCG TCG A }\end{array}$ & $454 \mathrm{bp}$ & KF699332.1 \\
\hline blasım-1 & $\begin{array}{l}\text { SIM1-F } \\
\text { SIM1-R }\end{array}$ & $\begin{array}{l}\text { TAC AAG GGA TTC GGC ATC G } \\
\text { TAA TGG CCT GTT CCC ATG TG }\end{array}$ & $571 \mathrm{bp}$ & AY887066.1 \\
\hline
\end{tabular}


ropenem 내성 Acinetobacter spp. 191주에 대하여 imipenem혹은 meropenem-Hodge 변법 시험을 시행하였 다. Imipenem에 의해서는 $A$. baumannii 121주, $A$. calcoaceticus 3 주 및 $A$. genomospecies 3 1주가양성을 보 였으며, meropenem에 의해서는 $A$. baumannii 가 74주, $A$. calcoaceticus 2 주, $A$. genomospecies 31 주가 양성을 보여 총 125 주의 carbapenemase 생성 균주를 검출하였다(Table 2). Acinetobacterspp. 균주를 대상으로 시행한 Hodge 변법 시험에서 meropenem 보다는 imipenem을 사용하는 것이 검 출율이 높았다.

\section{MBL 생성 균주}

Imipenem 혹은 meropenem-Hodge 변법시험에 양성인 균주에 대하여 imipenem 혹은 meropenem-EDTA+SMA DDS 양성인 Acinetobacter spp.는 imipenem에 의해서는 49주, meropenem에 의해서는 11 주가 $\mathrm{MBL}$ 생성 균주가 검출 되었다(Table 3). MBL 생성 Acinetobacter spp. 균주 검출시 $\mathrm{DDS}$ 시험에서 meropenem 보다 imipenem을 사용하는 것 이 4배 이상 검출율이 높았다.

\section{3. $\mathrm{MBL}$ 유전자 및 Integron}

Imipenem 혹은 meropenem-EDTA+SMA DDS 양성인 49주의 $\mathrm{MBL}$ 유전자 검출을 위하여 중합효소연쇄반응법을 이 용하였다. A. baumannii 29주와 A. calcoaceticus 1 주에서 blaviM-2 allele가 검출되었다(Table 3). 이들 균주들의 MBL 유
전형은 중합효소연쇄반응 산물을 염기서열 분석을 이용하여 모 두 blavIM-2 유전자임을 확인하였다. A. baumannii 16 주와 $A$. calcoaceticus 1주에서 bla|MP-1 allele가 검출되었으며, 염기 서열 분석으로 이들 균주들의 $\mathrm{MBL}$ 유전형은 모두 blaIMP-6임을 확인하였다. $A$. genomospecies 31 주에서 blaviM-2와 bla

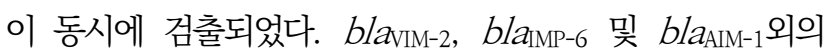

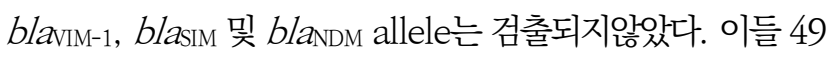
균주는 모두 class 1 integron이 검출되었다(Table 3). 또한, blaviM-2 혹은 bla $a_{\mathrm{IMP}-6}$ 를 갖는 integron은 aacA4유전자를 흔 히 갖고 있었고(data not shown), A. baumannii는 $2.8 \mathrm{~kb}$ 와 $3.2 \mathrm{~kb}$ 의 integron을 A. calcoaceticus는 $3.2 \mathrm{~kb}$ 와 $3.5 \mathrm{~kb}$ 의 integron을 $A$. genomospecies 3 는 $5.2 \mathrm{~kb}$ 와 $5.5 \mathrm{~kb}$ 의 integron이 검출되었다.

$\mathrm{MBL}$ 생성 Acinetobacter spp.는 객담 검체에서 28주 (57.14\%), 삽관에서 9주(18.37\%), 소변에서 7주(14.29\%), 농 에서 3주(6.12\%) 및 그 외 검체에서 2주(4.08\%)가 검출되었다 (Table 4). MBL 생성 A. baumannii는 객담, 삽관 및 소변에서 각각 27주, 9주 및 6주로 객담에서 가장 많이 검출되었고, $A$. calcoaceticus 1 주가 혈액에서 검출되었다. VIM-2 생성 Acinetobacterspp. 는 객담 검체에서 19주, 삽관에서 5주, 소 변에서 4주, 농에서 2주 및 창상에서 1주가 검출되었다. IMP-6 생성 Acinetobacterspp.는 객담, 삽관 및 소변에서 각각 9주, 4주 및 3 주가 검출되었고, 그 외 농과 혈액에서 각각 1 주씩 검출 되었다. VIM-2와AIM-1을 동시에생성하는 $A$ genomospecies 3 1 주는 창상검체에서 검출되었다.

Table 2. Results of Hodge test, double disk synergy test of Acinetobacter spp.

\begin{tabular}{|c|c|c|c|c|c|}
\hline \multirow{2}{*}{ Strains } & \multirow{2}{*}{$\begin{array}{l}\text { No. of } \\
\text { isolates }\end{array}$} & \multicolumn{2}{|c|}{ Hodge test positive strains } & \multicolumn{2}{|c|}{ Double disc synergy test positive strains } \\
\hline & & Imipenem & Meropenem & Imipenem & Meropenem \\
\hline A. baumannii & 187 & 121 & 74 & 45 & 7 \\
\hline A. calcoaceticus & 3 & 3 & 2 & 3 & 3 \\
\hline A. genomospecies 3 & 1 & 1 & 1 & 1 & 1 \\
\hline Total & 191 & 125 & 77 & 49 & 11 \\
\hline
\end{tabular}

Table 3. MBL gene types and integron classes of Acinetobacter spp.

\begin{tabular}{|c|c|c|c|c|c|c|}
\hline \multirow{3}{*}{ Strains } & \multicolumn{6}{|c|}{ No. of isolates } \\
\hline & \multicolumn{3}{|c|}{ MBL gene type } & \multicolumn{3}{|c|}{ Class of integron } \\
\hline & blavIM-2 & bla|MP-6 & bla $a_{\mathrm{AIM}-1}$ & Int1 & Int2 & Int3 \\
\hline A. baumannii & 29 & 16 & 0 & 45 & 0 & 0 \\
\hline A. calcoaceticus & 1 & 2 & 0 & 3 & 0 & 0 \\
\hline A. genomospecies 3 & 1 & 0 & 1 & 1 & 0 & 0 \\
\hline Total & 31 & 18 & 1 & 49 & 0 & 0 \\
\hline
\end{tabular}


448 Jong Hwa Yum. MBL-Producing Acinetobacter spp.

Table 4. Specimens of MBL gene PCR-positive Acinetobacter spp. isolates

\begin{tabular}{|c|c|c|c|c|c|c|c|}
\hline \multirow{2}{*}{ Specimens } & \multicolumn{3}{|c|}{ No. (\%) of MBL PCR-positive } & \multicolumn{4}{|c|}{ No. (\%) of isolates } \\
\hline & blavim-2 & blamp-6 & blaAIM-1 & ABA & ACA & AG3 & Total \\
\hline Sputum & 19 & 9 & 0 & 27 & 1 & 0 & $28(57.14)$ \\
\hline Catheter TIP & 5 & 4 & 0 & 9 & 0 & 0 & $9(18.37)$ \\
\hline Urine & 4 & 3 & 0 & 6 & 1 & 0 & $7(14.29)$ \\
\hline Pus & 2 & 1 & 0 & 3 & 0 & 0 & $3(6.12)$ \\
\hline Blood & 0 & 1 & 0 & 0 & 1 & 0 & $1(2.04)$ \\
\hline Wound & 1 & 0 & 1 & 0 & 0 & 1 & $1(2.04)$ \\
\hline Total & $31(62.00)$ & $18(36.00)$ & $1(2.00)$ & $45(91.84)$ & $3(6.12)$ & $1(2.04)$ & $49(100)$ \\
\hline
\end{tabular}

Abbreviations: ABA, A. baumannii; ACA, A. calcoaceticus; AG3, A. genomospecies 3 .

Table 5. MICs of antimicrobial agents for MBL-producing clinical isolates of Acineotobacter spp. in a Korean hospital

\begin{tabular}{|c|c|c|c|c|c|c|c|c|c|c|c|c|c|}
\hline \multirow{2}{*}{$\begin{array}{l}\mathrm{MBL} \\
\text { types }\end{array}$} & \multirow{2}{*}{$\begin{array}{l}\text { Strains } \\
\text { (No. of } \\
\text { isolates) }\end{array}$} & \multicolumn{12}{|c|}{ MIC range $(\mu \mathrm{g} / \mathrm{mL})$} \\
\hline & & IPM & MEM & AZT & CTX & CAZ & CEP & FOX & SAM & PIP & AMK & $\mathrm{CIP}$ & COL \\
\hline \multirow[t]{2}{*}{ VIM-2 } & ABA (29) & $16 \sim 64$ & $8 \sim 64$ & $16 \sim 128$ & $>128$ & $\begin{array}{l}64 \sim \\
>128\end{array}$ & $>128$ & $\begin{array}{l}64 \sim \\
>128\end{array}$ & $\begin{array}{l}32 \sim \\
>128\end{array}$ & $\begin{array}{l}64 \sim \\
>256\end{array}$ & $\begin{array}{c}4 \sim \\
>128\end{array}$ & $0.25 \sim 64$ & $0.25 \sim 4$ \\
\hline & ACA (1) & 16 & 8 & 64 & $>128$ & $>128$ & $>128$ & $>128$ & 64 & $>256$ & 32 & 32 & 0.5 \\
\hline \multirow[t]{2}{*}{ IMP-6 } & ABA (16) & $8 \sim 32$ & $8 \sim 32$ & $4 \sim 64$ & $>128$ & $\begin{array}{l}64 \sim \\
>128\end{array}$ & $>128$ & $>128$ & $\begin{array}{l}32 \sim \\
>128\end{array}$ & $64 \sim 256$ & $\begin{array}{l}128 \sim \\
>128\end{array}$ & $0.5 \sim 64$ & $0.25 \sim 0.5$ \\
\hline & ACA (2) & 16 & 16 & $32 \sim 64$ & $>128$ & $>128$ & $>128$ & $>128$ & $32 \sim 64$ & $\begin{array}{l}128 \sim \\
>128\end{array}$ & 128 & 16 & 0.5 \\
\hline $\begin{array}{l}\text { VIM-2 } \\
+ \text { +AIM-1 }\end{array}$ & AG3 (1) & 32 & 16 & 32 & $>128$ & $>128$ & $>128$ & $>128$ & 64 & $>128$ & $>128$ & 64 & 0.5 \\
\hline
\end{tabular}

Abbreviations: IMP, imipenem; MEM, meropenem; AZT, aztreonam; CTX, cefotaxime; CAZ, ceftazidime; CEP, cephalothin; FOX, cefoxitin; SAM, ampicillin/sulbactam; PIP, piperacillin; AMK, amikacin; CIP, ciprofloxacin; COL, colistin; ABA, A. baumannii;, ACA, A. calcoaceticus; $\mathrm{AG} 3$, A. genomospecies 3.

\section{4. $\mathrm{MBL}$ 생성 Acinetobacterspp.에 대한 항균제 감수성}

VIM-2 생성 $A$. baumannii에 대한 imipenem과 meropenem의 MIC는 각각 16 64 $\mu \mathrm{g} / \mathrm{mL}$ 와 8 64 $\mu \mathrm{g} / \mathrm{mL}$ 이었 고, ampicillin/sulbactam의 MIC는 32 128 $\mu \mathrm{g} / \mathrm{mL}$ 이었 고, cefotaxime, ceftazidime 및 cefoxitin의 $\mathrm{MC}$ 는각각 $>128$ $\mu \mathrm{g} / \mathrm{mL}, 64 \sim>128 \mu \mathrm{g} / \mathrm{mL}$, 그리고 $64 \sim>128 \mu \mathrm{g} / \mathrm{mL}$ 이었 고, 대부분의 $\beta$-lactam제제에 높은 MIC값을 보였다(Table 5). Aztreonam의 MIC는 $16 \sim 128 \mu \mathrm{g} / \mathrm{mL}$ 로 비교적 낮은 MIC을 보이는 균주도 있었다. Amikacin의 MIC는 4 >128 $\mu \mathrm{g} / \mathrm{mL}$ 이었고, colistin의 MIC는 $0.25 \sim 4 \mu \mathrm{g} / \mathrm{mL}$ 로 비교적 낮은 값을 나타냈다. VIM-2 생성 $A$. calcoaceticus는 $A$. baumannii와 유사한 결과를 보였고, colistin의 MIC는 0.5 $\mu \mathrm{g} / \mathrm{mL}$ 로 감수성이었다. IMP-6 생성 Acinetobacter spp.에 대 한 imipenem과 meropenem의 MIC는 모두 8 32 $\mu \mathrm{g} / \mathrm{mL}$ 로 MIC값이 유사한 경향을 보였다(Table 5). 이들 균주에 대한 ampicillin/ sulbactam의 MIC는 32 >128 $\mu \mathrm{g} / \mathrm{mL}$ 이었고, cefotaxime, ceftazidime, cefoxitin 및 aztreonam의 MIC
는각각 $>128 \mu \mathrm{g} / \mathrm{mL}, 64 \sim>128 \mu \mathrm{g} / \mathrm{mL},>128 \mu \mathrm{g} / \mathrm{mL}$ 및 $4 \sim 64 \mu \mathrm{g} / \mathrm{mL}$ 이었다. Amikacin의 MIC는 128 >128 $\mu \mathrm{g} / \mathrm{mL}$ 으로 IMP-6 생성 Acinetobacter spp.는 대부분의 $\beta$-lactam 제제에 대해 모두 높은 MIC 값으로 내성을 보였다. Colistin의 MIC는 $0.25 \sim 0.5 \mu \mathrm{g} / \mathrm{mL}$ 이었고, 이들 IMP-6 생 성 Acinetobacter spp. 모두 감수성이었다. AIM 생성 $A$. genomospecies 3 균주에 대한 imipenem과 meropenem 의 $\mathrm{MIC}$ 는 각각 $32 \mu \mathrm{g} / \mathrm{mL}$ 과 $16 \mu \mathrm{g} / \mathrm{mL}$ 로 meropenem의 $\mathrm{MIC}$ 값이 약간 낮았고, 다른 시험 항균제에 대해서는 Acinetobacter spp.와 유사한 결과를 보였다.

\section{고 찰}

2010년 E. coli, Enterobacter cloacae, P. aeruginosa 및 A. baumannii 등과 같은 그람음성 막대균을 대상으로 carbapenemase 생성균 선별에 imipenem-Hodge 변법시 험이 유용함을 Lee 등이 발표한 바 있다[19, 20, 25]. 본 연구에 서 imipenem혹은 meropenem-Hodge 변법시험을 시행한 
결과, A. baumannii 121주, A. calcoaceticus 3주 및 A. genomospecies 3 1주가 imipenem-Hodge 변법 시험에 양 성을 보였으며, A. baumannii 가 74주, A. calcoaceticus 2 주, $A$. genomospecies 31 주가 meropenem-Hodge 변법 시험에 양성을 보여 총 125 주의 carbapenemase 생성 Acinetobacter spp. 를 검출하였다(Table 2). Acinetobacter spp. 균주를 대상으로 carbapenemase 생성 균주 검출시 Hodge 변법시험에 meropenem보다는 imipenem을 사용하 는 것이 일선 검사실에서 균주 선별을 위해서는 유용성이 높은 것으로 나타났다. 그러나, A. baumannii 6주는 imipenem-Hodge 변법시험에서 음성을 보였으나 MeropenemHodge 변법시험에서 양성을 보여(data not shown), imipenem 디스크와 meropenem 디스크를 동시에 사용하는 것이 carbapenemase 생성 Acinetobacter spp. 선별시 검출율을 높일 수 있는 것으로 나타났다.

일선 검사실에서 그람음성 막대균 중 $\mathrm{MBL}$ 생성 균주를 선별 시 carbapenem-DDS 시험에 imipenem 디스크를 흔히 사용 하여 한다[19, 20]. 그러나, 일본의 Arakawa 등은 IMP-1을 생 성하는 Klebsiella penumoniae, Citrobacter freundii, $P$. aeruginosa 및 Serratia marcescens 등의 그람음성 세균중 $\mathrm{MBL}$ 생성 균주 선별에 사용하는 DDS 시험에 caftazidime을 이용하는 것이 유리하다고 보고한 바 있다[26]. 그러나, MBL 생 성 균주 선별에 imipenem-DDS 시험이 효율적이라고 보고한 연구자도 있다[19, 20]. 본 연구에서 imipenenm 혹은 meropenem 내성 A. baumannii 121주를 대상으로 유사 항균제인 imipenem과 meropenem을 사용한 DDS 시험에서 imipenem-DDS 시험에서 45주가 양성이고, meropenemDDS 시험에서 7주가 양성으로 나타나(Table 3), imiepenem 디스크를 사용하는 것이 meropenem을 사용하는 것 보다 6배 이상 효과적이었다. 이는 $\mathrm{MBL}$ 생성 세균 중에는 imipenem과 meropenem에 대한 가수분해 활성 차이로 인해 meropenem 을 이용한 DDS 시험에 음성 결과를 보이는 경우가 있는 것으로 추정된다. 따라서, 일선 검사실에서 $\mathrm{MBL}$ 생성 Acinetobacter spp. 검출시 DDS 시험에 imipenem 디스크를 사용하는 것이 효율적인 것으로 판단된다.

Surveillance of Multicenter Antimicrobial Resistance in Taiwan (SMART)의 조사 연구에서 7개의 주요 대형병원의 중환자실에서 검출한 $A$. baumannii complex 138 주 중 객담, 혈액 및 소변 검체에서 각각 115 주, 9 주 및 6주가 검출되어 주로 이들 균주는 객담에서 많이 검출되는 것으로 발표한 바 있다 [27]. 본 연구에서 $\mathrm{MBL}$ 생성 Acinetobacterspp.는 객담에서
28 (57.14\%)주가 검출되어 가장 많았고, 삽관과 소변 검체에서 각각 9 (18.38\%)주와7 (14.29\%)주가 검출되어 유사한 검출율 을 보였다.

Yong과 Yum 등은 국내 대학병원에서 imipenem 내성 Acinetobacterspp.는 1998년 이미 높은 분리율을 보고한 바 있고, 이들 세균은 1주는 bla|MP-1을 가지고 있었고, 13주는 blaviM-2를 가지고 있었고[28, 29], 계속적으로 이들 세균은 높 은 분리율을 보였다. 2004년 국내에서 분리한 Acinetobacter spp.중 30\%가 imipenem에 내성이었고, 이들 내성 균주의 $27 \%$ 정도는 $\mathrm{MBL}$ 생성 균주이었고, 이들 균주가 가지는 $\mathrm{MBL}$ 은 integron에 위치한 blaviM-2 allele가 64\%, blaIMP-1 allele가 29\%, 그리고 blasim-1 allele가 7\%로 높은 빈도를 보였다[29].

Imipenem에 내성인 MBL 생성 Acinetobacterspp. 에 대 한 분자생물학적 역학조사를 미국, 폴란드, 그리스 및 이태리 등 지역이나 국가에서 시행하여 보고하였다[21, 27, 30, 31]. 최근 이들 지역 연구에서 IMP와 VIM형 MBL의 출현이 만연한 것으 로 나타났다. 국내에서는 거리가 먼 유럽지역에서는 $\mathrm{MBL}$ 생성 그람음성 막대균에서 blavIM형이 높은 빈도로 검출되고, 상대적 으로 가까운 거리의 일본에서는 blalMP- 1 형이 주로 검출되었으 나, 국내에서는 1995년이후 blaviM-2형 MBL이 이 일정 기간 동 안 계속적으로 검출되었다[14, 32, 33]. 일본에서 발견된 blalMP-6이 국내 그람음성 세균에서도 출현하고 있다. IMP-6은 IMP-1과 비교하여 하나의 아미노산 서열만이 바뀌어 (Ser196Gly) penicillin에 대한 활성은 감소되고 meropenem 에 대한 활성이 증가한 것으로 알려져 있다[34]. 2009년부터 국 내에서 검출된 $\mathrm{MBL}$ 생성 $P$. aeruginosa과 같은 그람음성 막대 균에서 IMP-6 생성 균의 출현이 증가한 것으로 보고하였다 [35].

본 연구에서는 $\mathrm{MBL}$ 생성 $A$. baumannii 29주와 $A$. calcoaceticus 1 주에서 blavim-2를 검출하였고, A. baumannii 16 주와 A. calcoaceticus 2주에서 blalMP-6가 검출되었고 $A$. genomospecies 3 1주에서 blaviM-2와 blaAlM-1이 동시에 검출 되어 국내 $\mathrm{MBL}$ 생성 Acinetobacter spp.는 blaviM-2와 bla $a_{\mathrm{IMP}-6}$ 가 주로 전파되고 있고, bla $a_{\mathrm{AIM}-1}$ 를 가지는 세균도 출현 하는 것으로 나타났다(Table 3). 따라서, 국내에서 유행하는 $\mathrm{MBL}$ 생성 Acinetobacter spp. 간에는 bla $\mathrm{IIMP}_{\mathrm{IM}-6}$ 보다 blaviM-2 가 보다 많이 전파확산되고 있고, 이들 내성 유전자에 의한 imipenem 혹은 meropenem에 대한 내성 세균이 증가할 것 으로 판단된다.

2003년, 국내에서 SIM 생성 A. baumanni 6주가 출현하였 는데, 이 SIM 유전자는 class 1 integron에 있었다[9]. 내성 유 
전자가 integron에 위치하는 경우, 이들 유전자의 전달이 용이 할수 있는데, 본 연구에서 $\mathrm{MBL}$ 생성 Acinetobacter spp.에서 SIM 유전자는 검출되지 않았다(Table 3, 4). 이는 VIM과 IMP 효소에 비해 SIM은 imipenem이나 meropenem에 대한 가수 분해능이 상대적으로 낮아, 해당 항균제 압력이 있을 때 VIM이 나IMP와같은 내성 유전자를 보다 더 잘 가지고 있는 것으로 판 단된다. 또한, 과거 국내에서 출현한 $\mathrm{MBL}$ 생성 Acinetobacter spp.는 IMP-1을 주로 생성하였으나, 본 연구에서 IMP-6 생성 균주가증가하는 이유는 IMP-6가 meropenem에 대한 가수분 해 활성이 높은 것으로 판단되며, IMP-6 생성 균주는 계속적으 로 증가할 것으로 예상된다.

blaviM-2는 흔히 integron에 위치하는데, blaviM-2가 위치한 integron의 크기와 카세트 배열은 다양하게 보고되었다[14, $32,33,36-38]$. 캐나다에서 출현한 blaviM-2를 갖는 integron 은 $a a c C 1$ 과 $a a c A$ 를 함께 가지고 있었고[39], 미국에서 출현 한 blavin-2를 갖는 integron은 blavin-2는 두번째 카세트에 위 치하고, $a a c A 7, d h f r$ 및 $a a c C-A 5$ 를 함께 가지고 있었다[37]. 국내에서 2002년 Yum 등이 보고한 MBL 생성 $A$. baumannii 와 Acinetobacter genomospecies 3는 첫번째 카세트에 위 치한 blaviM-2를 갖는 integron, In105는 aacA7과 aadA1을 갖고 있었고, In106은 aacA4와 aadA1을 갖고 있었다[28].

본 연구에서는 blaviM-2 혹은 blaIMP-6를 갖는 integron은 aacA4유전자를 흔히 갖고 있었고(data not shown), A. baumannii는 $2.8 \mathrm{~kb}$ 와 $3.2 \mathrm{~kb}$ 의 integron을 $A$. calcoaceticus 는 $3.2 \mathrm{~kb}$ 와 $3.5 \mathrm{~kb}$ 의 integron을 $A$. genomospecies 3 는 $5.2 \mathrm{~kb}$ 와 $5.5 \mathrm{~kb}$ 의 integron이 검출되었다(Table 3 ). 또한 한 균주가 2개 이상의 integron을 흔히 가지고 있었다. 본 결과로 보아, Acinetobacterspp.는 시기와 지역에 따라 $\mathrm{MBL}$ 유전자 뿐 아니라 다양한 내성 유전자를 갖는 integron을 흔히 2개 이 상 가질 수 있는 것으로 보인다.

VIM-2 생성 Acinetobacterspp.와 IMP-6 생성 Acinetobacter spp.에 대한 imipenem의 MIC는 각각 16 64 $\mu \mathrm{g} / \mathrm{mL}$ 과 8 32 $\mu \mathrm{g} / \mathrm{mL}$ 이었고, meropenem의 MIC는 8 $64 \mu \mathrm{g} / \mathrm{mL}$ 과 8 32 $\mu \mathrm{g} / \mathrm{mL}$ 로 비교적 높은 값으로 내성이었고, ampicillin/sulbactam을 포함하여 대부분의 $\beta$-lactam제제 의 MIC가 높고 ciprofoxacin과 같은 다른 계열 항균제의 MIC 도 높은 균주도 많았다(Table 5). 이에 반해 colistin의 MIC는 $0.25 \sim 4 \mu \mathrm{g} / \mathrm{mL}$ 로 낮아 대부분 감수성이었다. 그러나, colistin 의 사용이 증가한다면, 이들 항균제에 대한 내성도 증 가할 것으로 예상되므로, Acinetobacter spp. 감염증 치료를 위한 새로운 항균제의 개발이 필요해 보인다.
$\mathrm{MBL}$ 생성 Acinetobacter spp.는 국내에서 계속적으로 높 은 검출율을 보이고 있다. VIM-2 생성 Acinetobacter spp.는 1990년대 이후로 계속적으로 높은 검출율을 보이고 있으며, IMP-6 생성 Acinetobacter spp. 점진적으로 증가하고 있는 추세이다. Sung 등은 2015년, IMP-1 생성 균주가 대부분이었 고, IMP-1과 NDM-1을 동시 생성하는 A. pittif를 국내에서 분 리 보고한 바 있다[17]. 호주에서 2012년, 검출된 AIM-1 생성 P. aeruginosa가 출현한[11] 이후 많은 보고가 없는 AIM-1과 VIM-2를 동시에 생성하는 $A$. genomospecies 3 도 나타나고 있어, 이들 MBL에 의한 carbapenem 내성 그람음성 세균의 증 가가 예상되므로 이들 균주의 추가 확산 전파를 효과적으로 방 지하기 위한 정책과 감염관리가 필요해 보인다. 또한, 다양한 나 라와 지역의 의료기관에서 $\mathrm{MBL}$ 생성 Acinetobacter spp.뿐 아니라 다양한 내성유전자를 가질 수 있는 integron을 갖는 균 주와 유전체의 전달로 imipenem과 같은 carbapenem을 포 함한 다제 내성 그람음성 세균 출현의 증가가 예상되므로, 계속 적이고 체계적인 분자 역학적 조사연구 등이 필요하다.

\section{요 약}

주요 획득성 metallo- $\beta$-lactamase (MBL) 유전자에 의해 매개되는 carbapenem 내성, 특히 Acinetobacterspp. 균종 의 임상 분리주에 대한 보고가 증가하고 있다. 본 연구에서 임상 에서 비중복으로 분리된 carbapenem 비감수성 Acinetobacter spp. 191주 중 125 (65.4\%)주가 imipenem 혹은 meropenem-Hodge 변법시험에 양성이었고, 49 (25.7\%)주가 imipenem-EDTA+SMA double disk synergy (DDS) 시험 에 양성이었다. blavin-2 allele와 blalMP-2 allele 검출을 위한중 합효소연쇄반응과 염기서열분석을 시행한 결과, A. baumannii 와 A. calcoaceticus에서 각각 29주와 1주가 blavin-2를 갖고 있었고, A. baumannii 16주와 A. calcoaceticus 2주가 blalMP-1을 갖고 있었다. A. genomospecies 3 는 blaviM-2와 blaAIM-1을 동시에 갖고 있었다. 이들 MBL 유전자는 모두 class 1 integron에 있었다. blavin-2 혹은 blalMP-6를 갖는 class 1 integron의 크기는 A. baumannii 분리주에서는 $2.8 \mathrm{~kb}$ 에서 $3.2 \mathrm{~kb}$ 이었고, $A$. genomospecies 3 분리주에서는 $3.2 \mathrm{~kb}$ 에 서 $3.5 \mathrm{~kb}$ 이었다. blavim-2는 대부분 class 1 integron에 첫번 째 혹은 두번째에 위치하였고, $a a c A$ 를 흔히 가지고 있었다. 다 양한 내성 유전자를 가질 수 있는 MBL 생성 Acinetobacter spp.뿐 아니라 다양한 내성 유전자를 가질 수 있는 integron의 전파로 imipenem이나 meropenem과 같은 carbapenem 
내성을 포함하여 다제 내성 그람음성 세균의 증가가 예상된다. 또한, 위중한 Acinetobacterspp. 감염증 치료를 위한 새로운 항균제 개발이 필요하다.

Acknowledgements: I thank Prof. Hyukmin Lee Yonsei University College of Medicine, Republic of Korea for providing clinical isolates collection. This work was supported by Dong-eui University Grant (201902050001). Conflict of interest: None

Author's information (Position): Yum JH, Professor.

\section{REFERENCES}

1. Kramer A, Schwebke I, Kampf G. How long do nosocomial pathogens persist on inanimate surfaces? A systematic review. BMC Infect Dis. 2006;6:130. https://doi.org/10.1186/1471-23346-130.

2. Fishbain J, Peleg AY. Treatment of Acinetobacter infections. Clin Infect Dis. 2010;51;79-84. http://doi.org/10.1086/653120.

3. Jose G-M, Rosario A-V. Multiresistant Acinetobacter baumannii infections: epidemiology and management. Curr Opin Infect Dis. 2010;23:332-339. https://doi.org/10.1097/Qc0.0b013e32833ae38b.

4. Visca P, Seifert H, Towner KJ. Acinetobacter infection-an emerging threat to human health. IUBMB Life. 2011;63:1048-1054. https://doi.org/10.1002/iub.534.

5. Chusri S, Chongsuvivatwong V, Rivera JI, Silpapojakul K, Singkhamanan K, McNeil E, et al. Clinical outcomes of hospital-acquired infection with Acinetobacter nosocomialis and Acinetobacter pittii. Antimicrob. Agents Chemother. 2014;58: 4172-4179. https://doi.org/10.1128/AAC.02992-14.

6. Wisplinghoff H, Paulus T, Lugenheim M, Stefanik D, Higgins PG, Edmond $\mathrm{MB}$, et al. Nosocomial bloodstream infections due to Acinetobacter baumannii, Acinetobacter pittii and Acinetobacter nosocomialis in the United States. J Infect. 2012;64:282-290. https://doi.org/10.1016/j.jinf.2011.12.008.

7. Singh $\mathrm{H}$, Thangaraj P, Chakrabarti. A. Acinetobacter baumannii. a brief account of mechanisms of multidrug resistance and current and future therapeutic management. J Clin Diagn Res. 2013;7:2602-2605. https://doi.org/10.7860/JCDR/2013/6337.3626.

8. Blair JM, Webber MA, Baylay AJ, Ogbolu DO, Piddock LJ. Molecular mechanisms of antibiotic resistance. Nat Rev Microbiol. 2015;13:42-51. https://doi.org/10.1038/nrmicro3380.

9. Lee K, Yum JH, Yong D, Lee HM, Kim HD, Docquier JD, et al. Novel acquired metallo- $\beta$-lactamase gene, blasim-1, in a class 1 integron from Acinetobacter baumannii clinical isolates from Korea. Antimicrob Agents Chemother. 2005;49:4485-4491. https://doi.org/10.1128/AAC.49.11.4485-4491.2005.

10. Walsh TR, Toleman MA, Poirel L, Nordmann P. Metallo-beta-lactamases: the quiet before the storm? Clin Microbiol Rev. 2005;18:306-325. https://doi.org/10.1128/CMR 18.2.306-325.2005.

11. Yong D, Toleman MA, Bell J, Ritchie B, Pratt R, Ryley H, et al. Genetic and biochemical characterization of an acquired sub- group B3 metallo- $\beta$-lactamase gene, bla AIM-1 , and its unique genetic context in Pseudomonas aeruginosa from Australia. Antimicrob Agents Chemother. 2012;56:6154-6159. https://doi. org/10.1128/AAC.05654-11.

12. Livermore DM, Woodford N. Carbapenemases: a problem in waiting? Curr Opin Microbiol. 2000;3:489-495.

13. Toleman MA, Simm AM, Murphy TA, Gales AC, Biedenbach DJ, Jones RN, et al. Molecular characterization of SPM- 1 , a novel metallo- $\beta$-lactamase isolated in Latin America: report from the SENTRY antimicrobial programme. J Antimicrob Chemother. 2002;50:673-679. https://doi.org/10.1093/jac/dkf210.

14. Poirel L, Naas T, Nicolas D, Collet L, Bellais S, Cavallo J-D, et al. Characterization of VIM-2, a carbapenem-hydrolyzing metallo- $\beta$-lactamase and its plasmid- and integron-borne gene from a Pseudomonas aeruginosa clinical isolate in France. Antimicrob. Agents Chemother. 2000;44:891-897. https://doi.org/10.1128/ aac.44.4.891-897.2000.

15. Watanabe JJ, Ko WC, Wu JJ. Transferable imipenem resistance in Pseudomonas aeruginosa. Antimicrob. Agents Chemother. $1991 ; 45: 1343-1348$.

16. Lee K, Lee WG, Uh Y, Ha GY, Cho J, Chong Y, et al. VIM and IMP-type metallo- $\beta$-lactamase-producing Pseudomonas spp. and Acinetobacter spp. in Korean hospitals. Emerg Infect Dis. 2003;9:868-871. https://doi.org/10.3201/eid0907.020753.

17. Sung JY, Koo SH, Kim S, Kwon GC. Emergence of Acinetobacter pittii harboring New Delhi metallo-beta-lactamase genes in Daejeon, Korea. Ann Lab Med. 2015;35:531-534. https://doi. org/10.3343/alm.2015.35.5.531.

18. Loffler FE, Sun Q, Li J, Tiedje JM. 16S rRNA gene-based detection of tetrachloroethene-dechlorinating Desulfuromonas and Dehalococcoides species. Appl Environ Microbiol. 2000;66: 1369-1374. https://doi.org/10.1128/aem.66.4.1369-1374.2000.

19. Lee K, Chong Y, Shin HB, Kim YA, Yong D, Yum JH. Modified Hodge test and EDTA-disk synergy tests to screen metallo- $\beta$-lactamase-producing strains of Pseudomonas and Acinetobacter species. Clin Microbiol Infect. 2001;7:88-91.

20. Lee K, Lim YS, Yong D, Yum JH, Chong Y. Evaluation of the Hodge Test and the imipenem-EDTA double disk synergy test for differentiating metallo-beta-lactamase-producing clinical isolates of Pseudomonas spp. and Acinetobacter spp. J Clin Microbiol. 2003;41:4623-4629. https://doi.org/10.1128/jcm.41. 10.4623-4629.2003.

21. Riccio ML, Franceschini N, Boschi L, Caravelli B, Cornaglia G, Fontana R, et al. Characterization of the metallo-beta-lactamase determinant of Acinetobacter baumannii AC-54/97 reveals the existence of bla(IMP) allelic variants carried by gene cassettes of different phylogeny. Antimicrob Agents Chemother. 2000;44: 1229-1235. https://doi.org/10.1128/aac.44.5.1229-1235.2000.

22. Levesque C, Piche L, Chantal L, Roy PH. PCR mapping of integrons reveals several novel combinations of resistance genes. Antimicrob Agents Chemother. 1995;39:185-191. https://doi.org/10.1128/aac.39.1.185.

23. Shibata N, Doi Y, Yamane K, Yagi T, Kurokawa H, Shibayama K, et al. PCR typing of genetic determinants for metallo- $\beta$-lactamases and integrases carried by gram-negative bacteria isolated in Japan, with focus on the class 3 integron. J Clin Microbiol. 2003;43:458-461. https://doi.org/10.1128/jcm.41.12.5407-5413. 
2003.

24. Clinical and Laboratory Standards Institute. Performance standards for antimicrobial susceptibility tests; approved standards M2-A8, 27th ed. Wayne PA: CLSI; 2017.

25. Lee K, Kim CK, Yong D, Jeong SH, Yum JH, Seo YH. et al. Improved performance of the modified Hodge test with MacConkey agar for screening carbapenemase-producing Gram-negative bacilli. J Microbiol Methods. 2010;83:149-152. https://doi.org/10.1016/j.mimet.2010.08.010.

26. Arakawa Y, Shibata N, Shibayams K, Kurokawa H, Yagi T, Fugiwara $\mathrm{H}$, et al. Convenient test for screening metallo-betalactamase producing gram negative bacteria by using thiol compounds. J Clin Microbiol. 2000;38:40-43.

27. Lai CC, Chen YS, Lee NY, Tang HJ, Lee SS, Lin CF, et al. Susceptibility rates of clinically important bacteria collected from intensive care units against colistin, carbapenems, and other comparative agents: results from the Surveillance of Multicenter Antimicrobial Resistance in Taiwan (SMART). Infect Drug Resist. 2019;12:627-640. https://doi.org/10.2147/IDR.S194482.

28. Yum JH, Yi K, Lee H, Yong D, Lee K, Kim JM, et al. Molecular characterization of metallo- $\beta$-lactamase-producing Acinetobacter baumannii and Acinetobacter genomospecies 3 from Korea: identification of two new integrons carrying the blavin-2 gene cassettes. J Antimicrob Chemother. 2002;49:837-840. https:// doi.org/10.1093/jac/dkf043.

29. Yong D, Choi YS, Roh KH, Kim CK, Park YH, Yum JH, et al. Increasing prevalence and diversity of metallo- $\beta$-lactamases in Pseudomonas spp., Acinetobacter spp., and Enterobacteriaceae from Korea. Antimicrob Agents Chemother. 2006;50:1884-1886. https://doi.org/10.1128/AAC.50.5.1884-1886.2006.

30. Fiett J, Baraniak A, Mrowka A, Fleischer M, Drulis-Kawa Z, Naumiuk L, et al. Molecular epidemiology of acquired-metallo- $\beta$-lactamase-producing bacteria in Poland. Antimicrob. Agents Chemother. 2006;50:880-886. https://doi.org/10.1128/ AAC. 50.3.880-886.2006.

31. Toleman MA, Biedenbach D, Bennett DM, Jones RN, Walsh TR. Italian metallo-beta-lactamases: a national problem? report from the SENTRY antimicrobial surveillance programme. J Antimicrob Chemother. 2005;55:61-70. https://doi.org/10.1093/ $\mathrm{jac} / \mathrm{dkh} 512$.
32. Lauretti L, Riccio ML, Mazzariol A, Cornaglia G, Amicosante G, Fontana $R$, et al. Cloning and characterization of blavin, a new integron-borne metallo- $\beta$-lactamase gene from a Pseudomonas aeruginosa clinical isolate. Antimicrob Agents Chemother. 1999; 43:1584-1590.

33. Lee K, Lim JB, Yum JH, Yong D, Chong Y, Kim JM, et al. blanı-2 cassette-containing novel integrons in metallo- $\beta$-lactamaseproducing Pseudomonas aeruginosa and Pseudomonas putida isolates disseminated in ad Korean hospital. Antimicrob Agents Chemother. 2002;46:1053-1058. https://doi.org/10.1128/aac.46. 4.1053-1058.2002.

34. Yano H, Kuga A, Okamoto R, Kitasato H, Kobayashi T, Inoue M. Plasmid-encoded metallo- $\beta$-lactamase (IMP-G) conferring resistance to carbapenems, especially meropenem Antimicrob. Agents Chemother. 2001;45:1343-1348. https://doi.org/10.1128/ AAC. 45.5.1343-1348.2001.

35. Seok Y, Bae IK, Jeong SH, Kim SH, Lee H, Lee K. Dissemination of IMP-6 metallo- $\beta$-lactamses-producing Pseudomonas aeruginosa sequence type 235 in Korea. J Antimicrob Chemother. 2011; 66:2791-2796. https://doi.org/10.1093/jac/dkr381.

36. Quinteira S, Souse JC, Peixe L. Characterization of In100, a New integron carrying a metallo-beta-lactamase and a carbenicillinase, from Pseudomonas aeruginosa. Antimicrob. Agents Chemother. 2005;49:451-453. https://doi.org/10.1128/AAC.49. 1.451-453.2005.

37. Lolans K, Queenan AM, Bush K, Sahud A, Quinn JP. First Nosocomial outbreak of Pseudomonas aeruginosa producing an integron-borne metallo- $\beta$-lactamase (VIM-2) in the United States. Antimicrob. Agents Chemother. 2005;49:3538-3540. https://doi.org/10.1128/AAC.49.8.3538-3540.2005.

38. Kim I-S, Lee NY, Ki C-S, Oh WS, Peck KR, Song J-H. Increasing prevalence of imipenem-resistant Pseudomonas aeruginosa and molecular typing of metallo- $\beta$-lactamase producers in a Korean Hospital. Microb. Drug Resistance. 2005;11:355-3558. https:// doi.org/10.1089/mdr.2005.11.355.

39. Pitout JD, Chow BL, Gregson DB, Laupland KB, Elsayed S, Church DL. Molecular epidemiology of metallo- $\beta$-lactamase-producing Pseudomonas aeruginosa in the Calgary health region: emergence of VIM-2-producing isolates. J Clin Microbiol. 2007;43: 458-61. https://doi.org/10.1128/JCM.01694-06. 